\title{
14 Bird Mortality and Welfare
}

Migrating birds are evolutionary adapted to overcome migration barriers, compensate for losses of fat deposits, and endure stress from being exposed to raptors in alien and unfriendly habitats, etc. In the cases of birds being caught, the ringing station and we, the ringers, constitute an additional stress factor, and contact with ringing activities adds to the risk of dying before the next breeding season, when the bird has a chance to pass its genes to the next generation. At any rate, a majority of all birds present in late summer, in passerines as much as to $85 \%$, will die on migration and in the winter season (Newton, 2008), irrespective of their meeting ringers or not; they would be condemned to death within some hours, days or at least months (Figure 14.1). In contrary, usually $99 \%$ of caught birds fly farther without too much disturbance (Figure 14.2). These statements give some distance to very emotional and sometimes hot discussions on the problem: are the catching losses in birds acceptable? Let's face the truth, and try to discuss this very serious problem in more detail.

Mortality among birds caught by bird ringers has many different objective causes.

Some birds die or are injured due to faulty catching technique, some are killed by raptors when caught and unable to escape, some die during the ringing process or soon after being released. This mortality, however, is not reason enough to stop ringing or other studies where caught birds are involved. We must keep in mind that

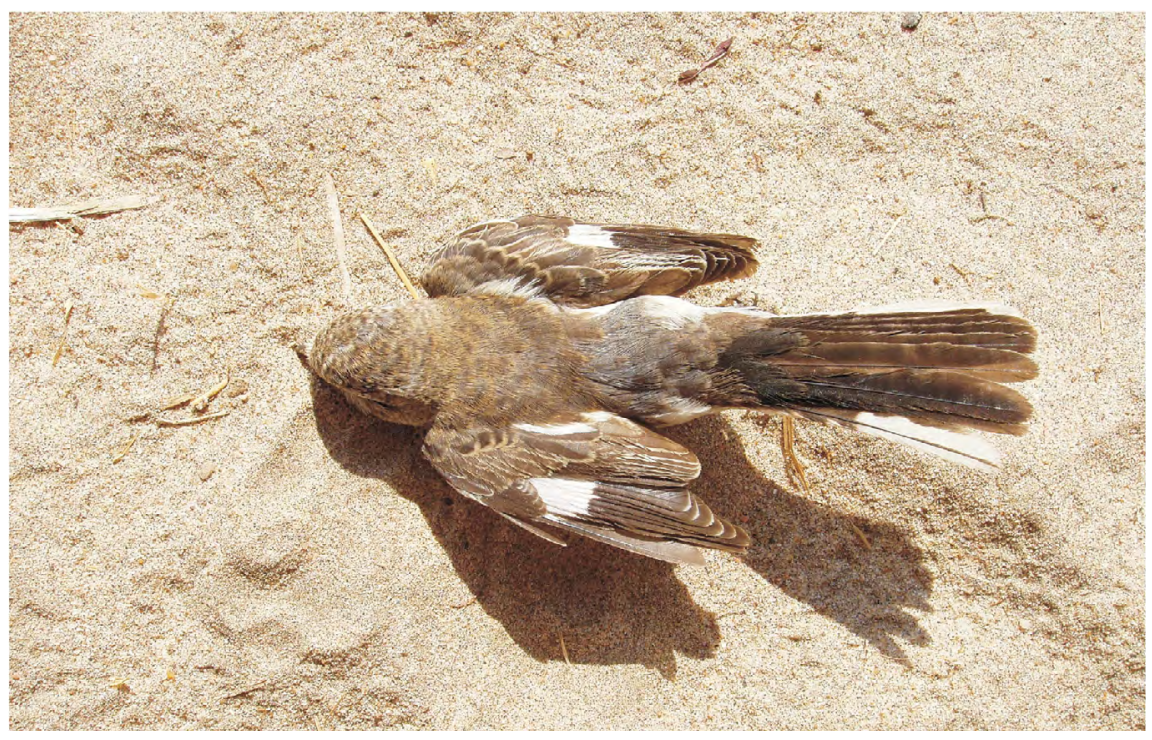

Figure 14.1: Natural death during migration. Most of migrants (up to 70-85\%) die during migration as a result of natural causes (here lack of energy stores during flight over a desert). Aswan, Egypt. Photo P. Busse. 

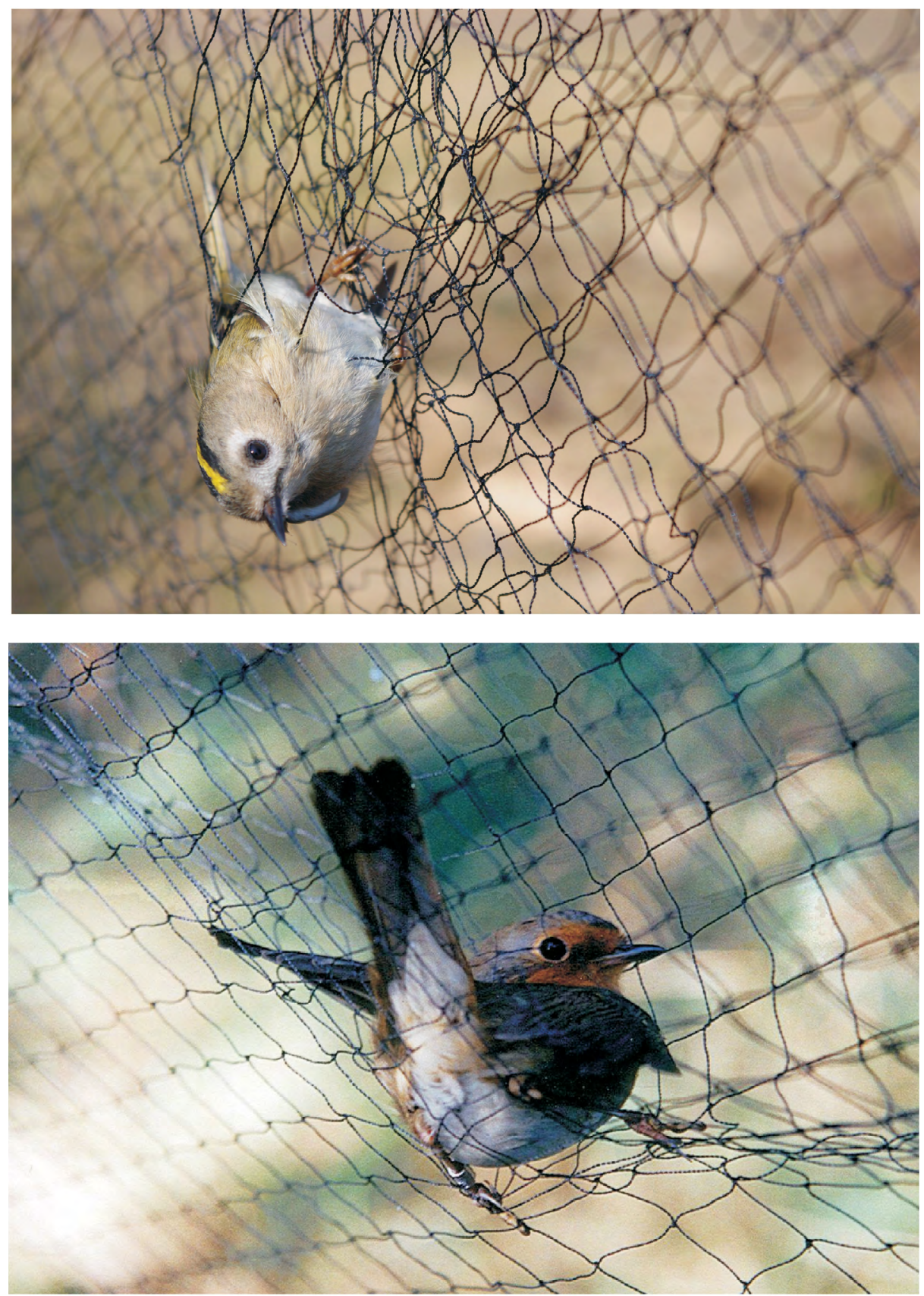

Figure 14.2: Most of migrants caught and ringed are still full of vigour and willing to fly farther. Photo P. Busse. 
ringing results may and will save many more birds in giving some advice on how to protect birds and their environments more effectively. At the same time, the fact that there is unavoidable mortality connected with ringing presents a strong obligation on ringers to make every effort in order to reduce losses among birds in their custody. This is the main reason why bird safety is a main topic in this Manual. The preventive theme is given particular emphasis in the Alarm Routine section. In the following section, a few more general comments are given, and a short summary collects advice presented in various parts of the text.

\subsection{Catching Devices}

The methods used when catching birds for scientific purposes are generally safe for the birds. However, "generally safe" does not mean that there are no birds injured or dead because of the catching device.

(a) Nets: Nets made of thin thread are intended for smaller species; when they catch larger species they are more likely to cause injury than nets made of thicker thread. The most common injuries are scars to the skin and cut-off tongues. Cases where birds hang themselves are comparatively rare; these occur in strong wind when birds are lifted out of the shelf and one mesh is pulled tight around the neck. Remedy: use thicker thread for standard catching.

Note that it is much safer for waders to use thicker thread for standard catching. It seems as if waders are more susceptible to injury in mist-nets than passerines living in woods or bushes. The latter are used to being rubbed or bumped against leaves and branches, and their bodies are stockier. Waders, on the other hand, are adapted to open and flat spaces and to running, but not to perching on branches. That is why they are more "soft-bodied", and therefore also more susceptible to injuries from the impact with mist nets (Meissner, 1992). Moreover, they fly with greater speed than passerines and the thin tread of wader-nets is more likely to cut the skin than the net designed for passerines. Still, mist-nets are very useful for catching waders, and in some areas, they are the only method available. Even at the ringing station, where the walk-in traps are the main catching tool, mist-nets may be used as an additional tool e.g. for catching birds attracted by tape luring at the night-time. When mist-nets are used to catch waders, they should preferably be watched continuously, and birds caught should be collected immediately. Old-fashioned, light-collecting binoculars will allow the ringer to check nets from a distance! Unexplainable cases of death are exceptional, although they occur where the bird hits the net and falls down into the shelf as is no longer alive. Sometimes, however, it may still be alive, but one could say it has fainted. This is probably caused by a psychological shock similar to that occurring in human life. The fainted bird may suddenly fly away - so do not put a bird apparently dead in your pocket! No remedy: accidents of this kind are unavoidable. 
(b) Walk-in traps: Birds already caught in traps are vulnerable to raptors, since the latter learn very quickly how to exploit this source of prey. Mammals will prey on trapped birds mainly at night or at dawn, whereas birds of prey or Corvids and Gulls will be active in the daytime. When raptors begin to penetrate the traps, night catching must be abandoned. In the daytime, the traps may be guarded, and raptors are shyer than waders. In addition, a special spring-trap on the roof of the walk-in trap will act as an effective deterrent. A bird of prey caught in that way should be removed immediately and transported at least $10 \mathrm{~km}$ from the ringing station. A good effect is obtained by placing additional fences along the walls of the capture chamber. They should be mounted with a slope and fixed to the trap. A second solution is to drive long twigs forked at top into the ground; this will make attacks by bird of prey from the air difficult (Figure 14.3).

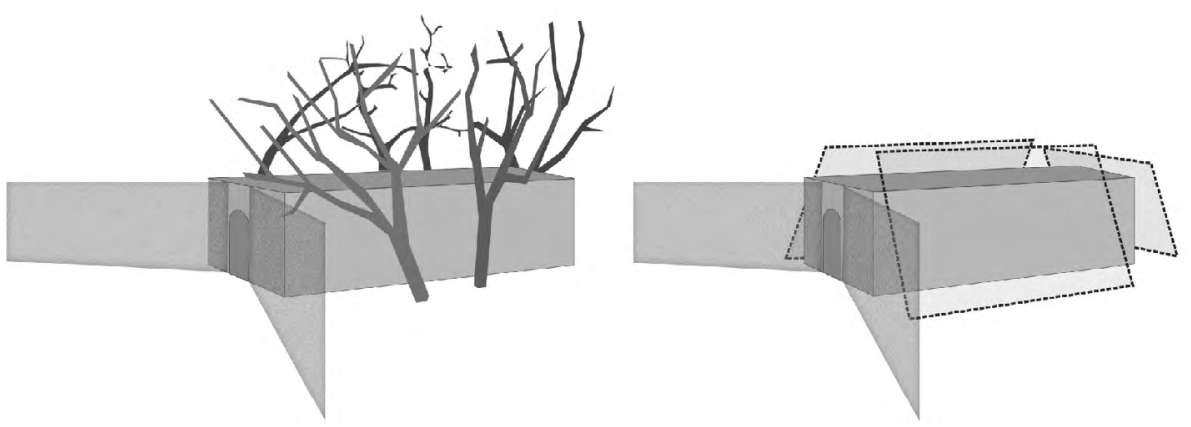

Figure 14.3: Protection of wader traps against winged raptors.

An electric fence positioned around catching site is very efficient against mammalian predators. When walk-in traps are placed along the coast, the total length of such fence becomes very high. However, the way of electric fence placement depends on the waterline shape and in some cases it is easier to separate the whole peninsula by short fence, than put long fence along the coast. The height of the fence should not be less than $50 \mathrm{~cm}$ with 8-9 wires between poles. The lowest wire might be unplugged, to allow passage of small animals. However, even a $50 \mathrm{~cm}$ high fence might be jumped over by foxes or feral cats. In such cases, a higher fence or two parallel lines of $50 \mathrm{~cm}$ high fence spaced apart about $1 \mathrm{~m}$ should be used.

(c) Heligoland traps: In the big Heligoland traps made from soft netting (nonmetal net), a bird may get stuck and strangle itself in the top section of the trap; the dimensions of the construction and the fragile walls in many cases render all rescue attempts futile. Since accidents of this kind are more probable when the netting is broken, loose, or incorrectly fixed to the construction lines, regular maintenance of the trap and stretching of the netting will serve as an at least partial remedy against these losses. 
In Heligoland traps with a terminal box, where birds fly against a glass pane, death as well as injury of birds entering the box at high speed occurs relatively often; blood effuses into the brain or eyes. Such constructions should not be used, or minimally, and the possibility of hitting the glass at high speeds should be reduced.

During mass trapping, the number of birds simultaneously collected in the final box should be limited by more frequent controls.

\subsection{The Catching Process}

All birds caught are readily accessible to raptors, and this is when the bird is hanging in a net or caught in a walk-in trap.

Avian raptors (especially the Sparrowhawk and Great Grey Shrike) hit the birds in the nets frequently. Local individuals are especially dangerous, as they learn quickly that the birds in the nets could be a source of food. However, they also learn quickly, that they can be caught, too. Remedy: there are limited chances to reduce such losses. In extreme cases, transport of a local individual far off the station area could be undertaken, if the bird will be caught. From the other point of view, however, these raptors naturally kill some birds to survive, so by netting potential victims, we make their hunting easier. In any case, some bird individuals are killed. During spring, migration of tits, especially great tits, in poor condition may kill other birds caught in the nets, sometimes, birds the size of thrushes. The brain of a killed bird is eaten first, followed by the rest of the body, and the ringer will find only bones and skin in the net. Tits are often caught when killing other birds and they usually continue to eat after being caught. Remedy: there is no possibility to eliminate such cases; the only action, which might reduce the losses, is not to remove killed birds as long as there is something to eat on them; new tits will not kill new individuals but clean the old corpses. This is a difficult strategy when visitors come to the catching area, however. Sometimes feeding the hungry birds with tallow from your butcher will help, but usually feeding is not overly effective since the birds are not residents of the catching site.

The most common wild mammal raptors killing birds in nets and traps are foxes, raccoons and different marten-like species. These animals are most active during night time, therefore they are most likely to attack owls and night migrants landing in the catching area early in the morning. Sometimes, however, specialized individuals of Marten and Ermine will attack and kill birds in broad daylight; Marten may develop into a sourge in reedbeds. Remedy: in practice there is no effective remedy against these raptors where mist-nets are used; in some cases, blood flour, used to intimidate stray dogs or spraying the net stands with fetor chemicals (e.g. some phosphoroorganic pesticides) may help; endangered wader traps should not be active during the night time. 
Domestic animals harm netted and trapped birds mainly when they are wild. Wild grown cats may pose a threat to netted birds, while wild dogs bring about more damage to trapped waders. Remedy: use of cat traps may solve the problem.

An electric fence may be helpful to exclude catching area from mammalian predators. However, sometimes fences should be very long, thus expensive. The other, less expensive solution could be ultrasonic devices used as mammals' repellents (dogs, martens and others).

\subsection{Birds and the Weather/Habitat Factor}

This is a parallel to the bird and the net/predator problem: birds in the nets and traps are exposed to weather and they may drown in rising water.

(a) A bird caught in a net is practically immobilized; its feathers pressed to the body, its head often pointing downwards, and its legs locked above the body. This unnatural position will affect the thermo-regulative abilities of the individual bird. At the same time, the whole body is exposed to heat, cold, rain, and insects more than usual. Low temperatures will cool the body below the physiologically acceptable level, and the bird will die if not removed soon enough. A similar threat is posed by high temperatures (above $30-32{ }^{\circ} \mathrm{C}$ ) day or exposure to direct sunrays in sheltered place, e.g. in orientation test stand. The impact of the cold is aggravated if the bird gets wet. So, the first remedy to losses of this kind is regular and more frequent checks of the nets, particularly in rainy weather or when the fog condenses on the birds. Usually, short showers are harmless to the birds, but a heavy rain during a thunderstorm will kill small species. Birds removed from nets in rainy weather are wet and must be dried as soon as possible. In most cases storing them in dry cotton bag is enough, but note: synthetic fabric has a very low capacity to absorb water, and the bird in such bag should be dried with an artificial heat-source, but, caution must be taken not to overheat it! When the bird is soaked through and cold stiff, the best drying method is to put it directly against your breast, i.e. not in a bag or between shirt and sweater! The method is not pleasant to the bird holder, especially if the birds name is e.g. Woodpecker, but, remember that you are responsible for the situation! It is a good custom to change the control rhythm when a thunderstorm is approaching. E.g. many reedbed birds become very active and are caught more frequently just before the storm. So, weather losses may be partly reduced by good attendance to the nets.

Birds caught in mist-nets, particularly the ones hanging in the lowest shelf, also run the risk of being overlooked at a regular control walk. Under normal conditions, leaving a bird for one hour does not endanger its life. When the control is the last one in the evening, however, the bird will hang in the net for a couple of hours, and the following morning it will be dead. So, the evening control must be very scrupulous, using a good lamp and checking the whole length of each net. Shaking of the net up and down when lighted will reveal birds caught in the bottom shelf or near the 
top string (such sporadic catches are frequently overlooked). Cleaning the nets from leaves in the evening will facilitate the night controls.

(b) Birds netted in reedbeds, where water is standing under the nets, run the risk of drowning. At sites where the water level is stable, strict adherence to the advice in Arrangement of the Netting Area: Wetland Habitats will reduce accidental losses. In reedbeds, where the water level changes highly and frequently, netting is much more risky. First of all, the lowest string must be held much higher than in places with stable water; Water level should be continuously monitored, and when flood is expected, the nets should be pulled high.

Wader traps frequently get flooded by rising water and the birds run the risk of being drowned, particularly on sea-shores, and in lagoons subject to the changes of the overall sea level. The sea level changes with tides, currents, air pressure and direction and force of winds. In the daytime, the distribution of traps must be adjusted to changing water levels and weather. Any decision to leave active traps overnight should be based on knowledge of the local water situation; if there is any doubt, move the traps from the catching area to higher ground.

\subsection{Removal and Transport of Birds Caught}

The removal of birds from nets and traps is a potential source of loss and/or injury.

(a) When birds are freed from a net, it must be remembered that bird legs and bird wings (in spite of their flexibility) must not be moved too rapidly or with excessive power; never apply force perpendicular to a leg. This usually leads to a fracture; the most common injury when removing birds from nets. The same thing, injury to the bird, may happen if it is allowed frequently flapping of the wings. One single strong wing-beat may break the air sack connecting the body sack with the wing bone, or cause blood effusion to the lungs, and the bird will be unable to fly, at least for a couple of days. Most vulnerable to this kind of injury are juvenile bullfinches, chaffinches, greenfinches, flycatchers and tree pipits. Other species, like goldcrests, yellow wagtails and hirundines seem to be totally unaffected.

A great deal of bird mortality results from incorrect handling of birds during transport. Remedy: strictly apply all advice given within appropriate sections above (see p. 31). In spite of how inconvenient they may be to you, follow them!

\subsection{Laboratory Work}

Laboratory work is relatively safe to the birds. On peak days, apply the advice given in the Alarm Routine section. Remember that even under normal conditions, birds must never wait for ringing and/or additional processing while exposed to direct sun radiation. The ringing procedure frequently reveals all mistakes made by the staff 
when removing and transporting the birds: the ringer may find dead or injured birds in the bags, others are unable to fly after being ringed. Discuss the matter with the people responsible! Dead birds should be noted in the field-form and the cause of death, if known, should be given as a comment. This procedure does not help the dead bird, but it can serve to explain losses and find remedies against them.

Injured birds should be treated according to the particular kind of the injury:

(a) A bird with broken wing bones or leg fracture above the tarso-metatarsal joint should be put to death, since it has no chance for a normal life or at least must pay for life with prolonged pain.

(b) A bird's leg with an open fracture of the tarso-metatarsal joint or tarsus should be amputated ca. $5 \mathrm{~mm}$ below the joint (use sharp scissors). Birds with cut-off tarsi are observed rather frequently in the nature as victims of natural hazards, and they may be in quite good condition. Releasing such birds without amputation will cause prolonged pain and the broken leg may be fixed in an unnatural position, handicapping the individual for the rest of its life-time. However, it should be mentioned that amputation of the bird tarsus by laymen is illegal under welfare legislation of most EU countries, but transport of a small bird to the veterinary would be practically impossible and result in prolonged stress, pain and even death. Usually, for the small bird such amputation means one drop of blood, fixed quickly.

(c) A broken tarsus, where the bones are not displaced, should not be amputated since there is a chance that ends may join in a natural process; it is obvious that the bird should not be ringed on that leg and/or do not ring the bird at all.

(d) Birds that are unable to fly will be handicapped in different ways; some of them temporarily paralysed by fright, it is relatively common in thrushes; within a couple of minutes, they suddenly fly away showing no flight handicap whatsoever. Others cannot fly because of a broken air-sack or internal blood effusion, allow such birds to walk away on foot as there is no way to help them: some of them will die, others will be taken by raptors but some will recover and continue their migration (a Bullfinch with such an injury was recovered seven days later several hundred kilometres south of the ringing place).

Some wader species are especially vulnerable to stress after catching. This mainly applies to long-legged species such as the Bar-tailed Godwit, Curlew, Whimbrel and larger species of genus Tringa. One effect of stress may be a leg or wing cramp. Birds affected in this way look healthy but are unable to stand on their legs. Relatively few such cases occur when waders are caught with walk-in traps, more often when cannon or rocket nets are used, and most frequent with mist-nets, particularly if the birds are allowed to hang for some time. The possibility for stress myopathy also increases on hot days and in birds with poor condition. In order to minimize these 
effects, particular attention should be paid to the regularity of controls and to the proper construction of containers for birds. Vulnerable species and individuals that sit in the container instead of standing up should be ringed first. If a leg cramp occurs and the bird is unable to stand up and fly away, it should be left in peace away from people, preferably in a place where other individuals of the same species stay, for about 1-3 hours. If this does not help, the bird should be placed in a spacious and high (ca. $50 \mathrm{~cm}$ ) container with free access of air and light, but not exposed to the sun! The bird should not be disturbed, the staff must avoid appearing in the bird's field of vision and to handle it any more. Water must be available in the container, but the edge of a rather deep vase containing water, must be placed at the ground level. If the leg cramp does not cease, it will be necessary to feed the bird. Smaller species quite willingly feed in captivity. Food should contain live "worms", e.g. earthworms, tubifex, nereids. The best way is to place them in a separate vase and supply 2-3 times a day. When the bird is unable to eat on its own it must be fed "by force". In addition a solution of glucose may be given every 2 hours. In most cases such a bird gets better within 5-6 days and can be freed. Some authors recommend giving ca. $0.5 \mathrm{mg}$, or in case of large birds, $1 \mathrm{mg}$ of Valium (diazepam) with water and food just after the leg cramp has occurred. After such a treatment, the bird will sleep up to ten hours or even more. It should be left in peace in place that is not too warm. When it wakes up, it should be able to walk normally. Bathing the legs of birds with incipient cramp in water may also be an effective treatment in cold weather. In hot conditions it is advisable to reduce density of caught birds in containers by ringing a proportion of them (30-50\%) from each compartment. Moreover, birds that are sitting in containers, and therefore are likely to become cramped, should be ringed and released first.

(e) A separate group of handicapped birds are those exhausted by the migration journey and then caught; they may lack energy reserves even to fly away from the laboratory. After some time, most of them will be able to move to nearby foraging areas and have a chance to rebuild their fat reserves, but some of them, regrettably, are unable to fly even this short distance and usually die. Such birds may survive if heated for a while or being given a glucose solution (one tea-spoon per hundred grams of water). Otherwise they will be victims of, a slightly artificial selection pressure eliminating the weakest individuals from the population. At any rate, try to minimize behaving as a selection tool!

If all remedies were applied, all possible cautions observed and care performed, and we have a dead bird, try to use its corpse for special studies. Sex criteria may be checked by inspecting the gonads, the lipid contents may be investigated, internal parasites collected (Figure 14.4), blood samples taken, etc. In that case the death of a bird will not only mean loss. But not all corpses are needed, and they should be instantly buried for sanitary reasons and to prevent bitter comments from the public. 


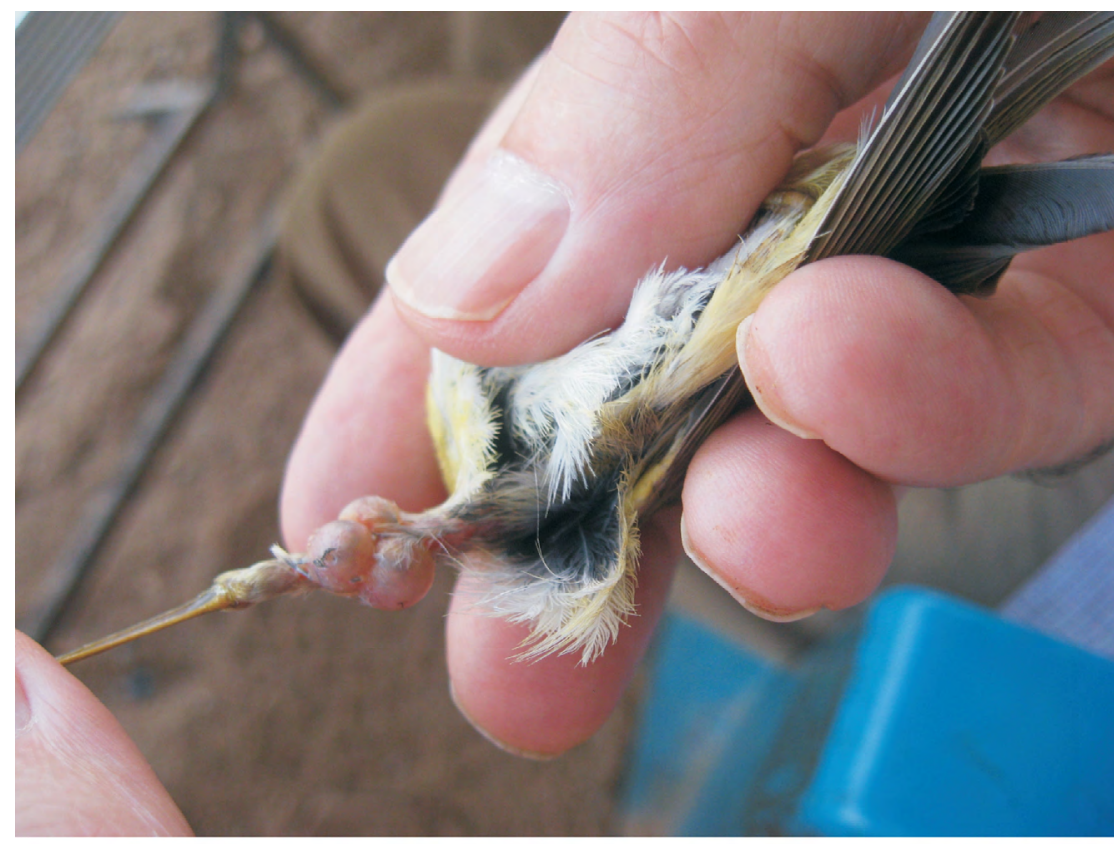

Figure 14.4-1: Collecting special data: here tumours caused by trematodes. Wadi Allaqi, Egypt. Photo I. Rząd.

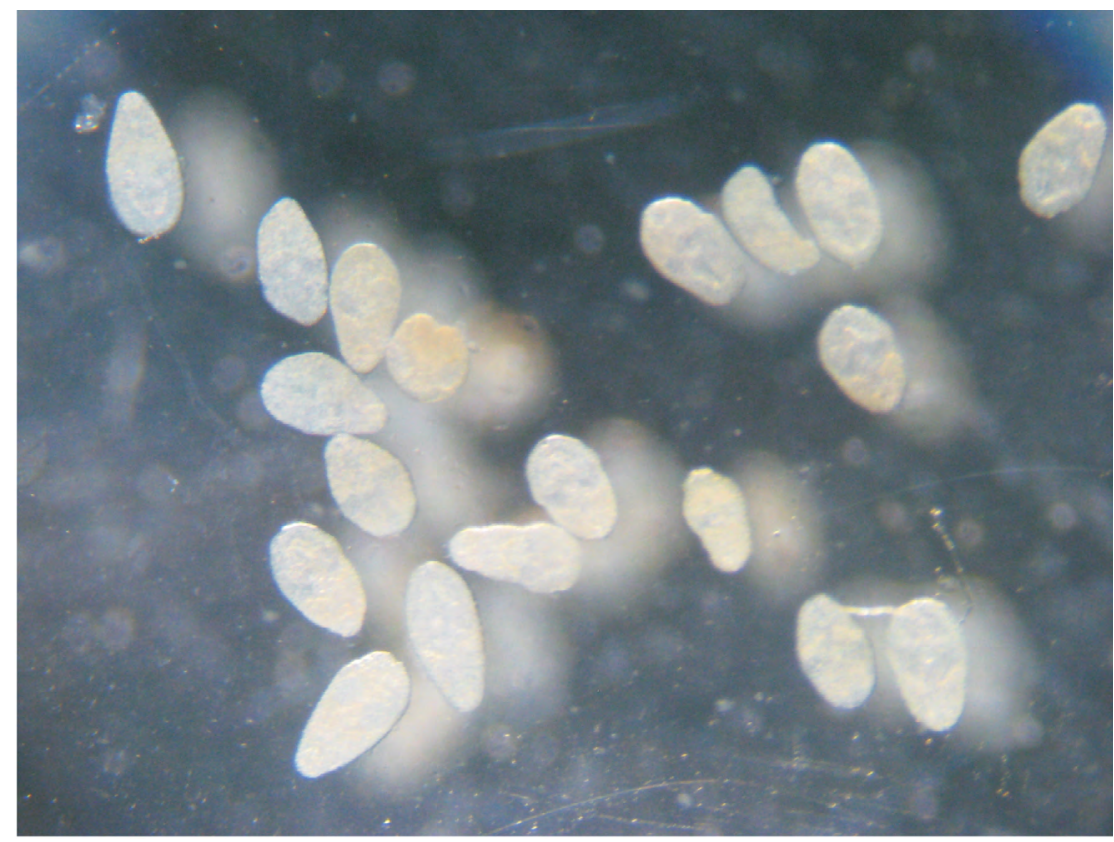

Figure 14.4-2: Collecting special data from a dead bird: high number of parasites in dead Swallow. Wadi Allaqi, Egypt. Photo I. Rząd. 